\title{
Geostatistical and texture analysis of airborne-acquired images used in forest classification
}

\author{
CHENGQIAN ZHANG
}

Department of Geography, University of Calgary, Calgary, Alberta, T2N 1N4, Canada; e-mail: czhan@ucalgary.ca

STEVEN E. FRANKLIN*

University of Saskatchewan, Box 5000 RPO University, 110 Gymnasium Place, Saskatoon, Saskatchewan, S7N 4J8, Canada; e-mail:S Steven.Franklin@usask.ca

and MICHAEL A. WULDER

Canadian Forest Service, Pacific Forestry Centre, Natural Resources Canada, Victoria, British Columbia, V8Z 1M5, Canada; e-mail: Mike.Wulder@nrcan-rncan.gc.ca

(Received 3 October 2002; in final form 13 August 2003)

\begin{abstract}
Airborne sensor image texture derived following a geostatistical analysis can increase the accuracy of forest classification because the resulting texture is insensitive to random variations in spectral response but related to the structural features of interest at the scale of a forest inventory (e.g. tree species). The combination of spectral and textural data derived from a kriging surface provided $86 \%$ classification accuracy in 36 pure and mixed-wood stands in seven forest classes in Alberta. This is an increase over the classification accuracy obtained when texture was derived from the original image data, and when the spectral response patterns were used alone.
\end{abstract}

\section{Introduction}

Many of the sources of error or uncertainty in the application of grey-level cooccurrence image texture (Haralick et al. 1973) to forest classification have been identified (Franklin et al. 2000). Among the more significant influences are: the choice of the texture measure (Carr and Pellon de Miranda 1998), the area or window size for the texture calculation (Marceau et al. 1990), and the choice of the input data layer from which texture measures are derived (Carr 1996). With respect to this latter point, while spatial resolution and scale of the image are always of fundamental concern (Treitz and Howarth 2000), different ways of preparing the image data for input to a texture analysis procedure have been only rarely discussed. Typically, the use of summary, 'grey-level vector-reduced' input data

\footnotetext{
*Author to whom correspondence should be addressed.
} 
(such as band ratios, vegetation indices, or principal component data) has been suggested (Marceau et al. 1990, Gong and Howarth 1992). However, grey-level cooccurrence matrices used to derive second-order texture measurements may be highly sensitive to small variations in pixel values within small windows. This influence may be augmented when using fine spatial resolution 'grey-level vectorreduced' input data. Relatively large window sizes can provide stable and accurate estimation of texture distributions from such data, and may even decrease random error. The resulting textures are appropriate at a particular scale (usually the forest stand-level) of forest mapping (Franklin et al. 2000).

Recently, filtered image data generated by kriging or smoothing functions have been shown to provide useful description of texture (Wen and Sinding-Larsen 1997, Oliver et al. 2000, Van Meirvenne and Goovaerts 2002). The idea is that geostatistical image transformation may be appropriate for interpretation of spatial structure in fine spatial resolution images and other spatial datasets because noise and 'unwanted' spatial variations are reduced prior to the extraction of textural information (Lévesque and King 1999, Muinonen et al. 2001). Image data represent ground features with various spatial variability components, which are nested within each other, as well as image noise introduced during data collection processing. The nested spatial variability components and noise can be decomposed into individual components with different spatial variability, because each component has its own variogram model specific to a certain spatial scale (Wen and Sinding-Larsen 1997). A geostatistical approach typically involves: computation of the image semivariogram, which is then used to model the spatial correlation structure in an image by decomposing the nested spatial variations into independent spatial components, and kriging analysis, which is required to estimate or interpolate local pixel variables using image data and the parameters of the semivariogram. This Letter aims to show that this use of the image semivariogram and kriging analysis, prior to the derivation of grey-level co-occurrence texture features from fine spatial resolution airborne sensor images acquired over several pure and mixed-wood stands in Alberta, can increase forest classification accuracy.

\section{Study area and methods}

\subsection{Study area}

The study area is located (figure 1) in the Kananaskis Valley on the eastern slope of the Rocky Mountains in Alberta, Canada. This area lies within a transition zone from a mountainous region to the foothills. Forest stands are predominantly composed of lodgepole pine (Pinus contorta), white spruce (Picea glauca), balsam poplar (Populus balsamifera) and trembling aspen (Populus tremuloides). The understorey is dominated by bearberry (Arctostaphylos rubra), creeping juniper (Juniperus horizontalis), and hairy wild rye (Elymus innovatus). Multistorey stands are common.

A total of 36 fixed-area $\left(100 \mathrm{~m}^{2}\right)$ plots in seven forest classes were established and conventional forest inventory information collected (table 1). On 18 July 1998, the Compact Airborne Spectrographic Imager (CASI) (Gray et al. 1997) was flown over the study area close to solar noon (approximately 13:40 local time) during clear atmospheric conditions. The spatial resolution was $2 \mathrm{~m}$, and the image was georeferenced with ground control to the available digital base map. The radiance data were converted to reflectance, in six visible and near-infrared bands ranging between 400 and $950 \mathrm{~nm}$, using an atmospheric model based on pseudo-invariant reflectance measurements acquired during the overflight (e.g. Richter 1990). The 36 


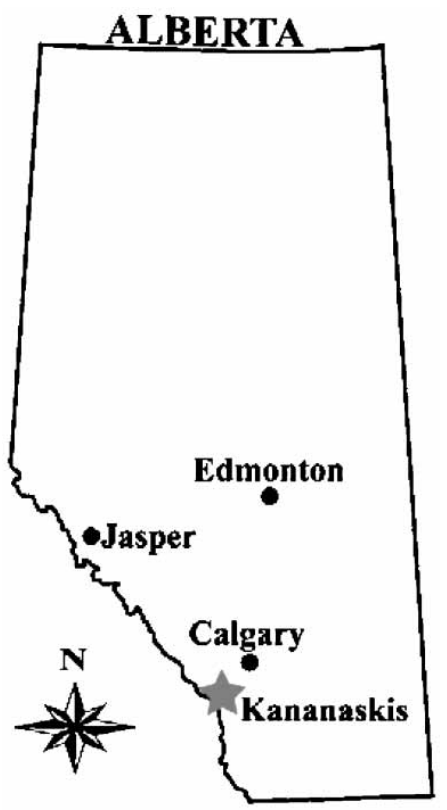

Figure 1. Location of the Kananaskis study area in south-western Alberta, Canada. The study area is centred at $51^{\circ} 1^{\prime} 13^{\prime \prime} \mathrm{N}, 115^{\circ} 4^{\prime} 20^{\prime \prime} \mathrm{W}$.

field plots were located on the image and image variables extracted for input to a linear discriminant analysis (LDA) classifier. Accuracy in an independent sample of plots not used in training the classifier was determined to be the agreement (per cent classification accuracy and the kappa coefficient, $K_{\text {hat }}$ ) between the observed classes of forest structure and the predicted class membership based on the LDA decision rule. Several classifications were completed with the decision rule consisting of various combinations of input data.

\subsection{Methods}

Semivariance $\gamma(h)$ describes the dependence of spatially correlated points $x$ and $x+h$, where $h$ is the lag interval within a distribution of the regionalized variable

Table 1. Forest classes with multilayer species composition labels based on 36 forest plots measured in the field $(\mathrm{Aw}=$ aspen, $\mathrm{Pl}=$ lodgepole pine, $\mathrm{Sw}=$ white spruce, $\mathrm{Pb}=$ balsam poplar, $\mathrm{Fd}=$ Douglas fir; species proportions expressed in increments of per cent $\times 10$ ).

Field label (species composition)

\begin{tabular}{llll}
\cline { 2 - 4 } Forest class & $\mathrm{Upper}$ layer & Second upper layer & Lower layer \\
\hline Class 1: Aspen & $\mathrm{Aw}_{10}$ & $\mathrm{Aw}_{10}$ & \\
Class 2: Aspen/Pine mixed-wood & $\mathrm{Aw}_{7} \mathrm{Pl}_{3}$ & $\mathrm{Aw}_{10}$ & $\mathrm{Aw}_{7} \mathrm{~Pb}_{2} \mathrm{Sw}_{1}$ \\
Class 3: Pine/Spruce/Aspen mixed-wood & $\mathrm{Pl}_{4} \mathrm{Sw}_{3} \mathrm{Aw}_{3}$ & $\mathrm{Pl}_{6} \mathrm{Sw}_{2} \mathrm{~Pb}_{1} \mathrm{Aw}_{1}$ & $\mathrm{Sw}_{5} \mathrm{Pl}_{5}$ \\
Class 4: Pine & $\mathrm{Pl}_{10}$ & $\mathrm{Pl}_{10}$ & $\mathrm{Pl}_{7} \mathrm{Aw}_{3}$ \\
Class 5: Pine/Spruce mixed-wood & $\mathrm{Pl}_{6} \mathrm{Sw}_{4}$ & $\mathrm{Sw}_{6} \mathrm{Pl}_{2} \mathrm{Aw}_{2}$ & $\mathrm{Sw}_{10}$ \\
Class 6: Spruce & $\mathrm{Sw}_{10}$ & $\mathrm{Sw}_{5} \mathrm{~Pb}_{3} \mathrm{Aw}_{2}$ & $\mathrm{~Pb}_{8} \mathrm{Aw}_{2}$ \\
Class 7: Spruce/Pine mixed-wood & $\mathrm{Sw}_{5} \mathrm{Pl}_{4} \mathrm{Fd}_{1}$ & $\mathrm{Sw}_{10}$ & $\mathrm{Sw}_{10}$ \\
\hline
\end{tabular}


$z(x)$ (Matheron 1963, Curran 1988):

$$
\gamma(h)=\frac{1}{2 N(h)} \sum_{N(h)}[z(x)-z(x+h)]^{2}
$$

where $N(h)$ is number of lag pairs separated by $h$. The second-order stationarity assumption, a valid assumption for an image, suggests that the semivariance function $(2 \gamma(x, x+h)=\operatorname{Var}[z(x)-z(x+h)])$ is invariant with location $x$. A model with a residual sum of squares value of 0.008 was used to describe the shape of the image semivariogram in four directions $\left(0^{\circ}, 45^{\circ}, 90^{\circ}\right.$ and $\left.135^{\circ}\right)$ (figure 2 ). Block kriging (Roberston 2000) was used to estimate local values $\hat{z}\left(x_{0}\right)$ from surrounding points $z\left(x_{i}\right)$ based on the spatial relationships provided by the semivariogram:

$$
\hat{z}\left(x_{0}\right)=\sum_{i=1}^{N} \lambda_{i} z\left(x_{i}\right)
$$

where $\lambda_{i}$ are weights, and $\sum_{i=1}^{N} \lambda_{i}=1$ assures unbiased estimation (the original pixel mean is unchanged) (Oliver et al. 2000).

Three grey-level co-occurrence texture measures (Haralick et al. 1973) were extracted from pre- and post-estimation images for each forest plot using an interpixel distance of 1 and a window size of $19 \times 19$ pixels based on the results of image texture tests in similar forests in New Brunswick and Alberta (Franklin et al. 2001):

$$
\begin{gathered}
\text { Angular Second Moment(ASM })=\sum_{i=1}^{m} \sum_{j=1}^{n}\{P(i, j)\}^{2} \\
\text { Contrast }(\mathrm{CON})=\sum_{i=1}^{n} \sum_{j=1}^{m} P(i, j)\{R(i)-C(j)\}^{2}
\end{gathered}
$$

Correlation $(\mathrm{COR})=\sum_{i=1}^{m} \sum_{j=1}^{n} \frac{P(i, j)\left[R(i)-\text { Mean }_{-} R(i)\right]\left[C(j)-\text { Mean }_{-} C(j)\right]}{\sqrt{\left\{\left(\text { Variance } \_R(i)\right)\left(\text { Variance }_{-} C(j)\right)\right\}}}$

\section{Variogram}

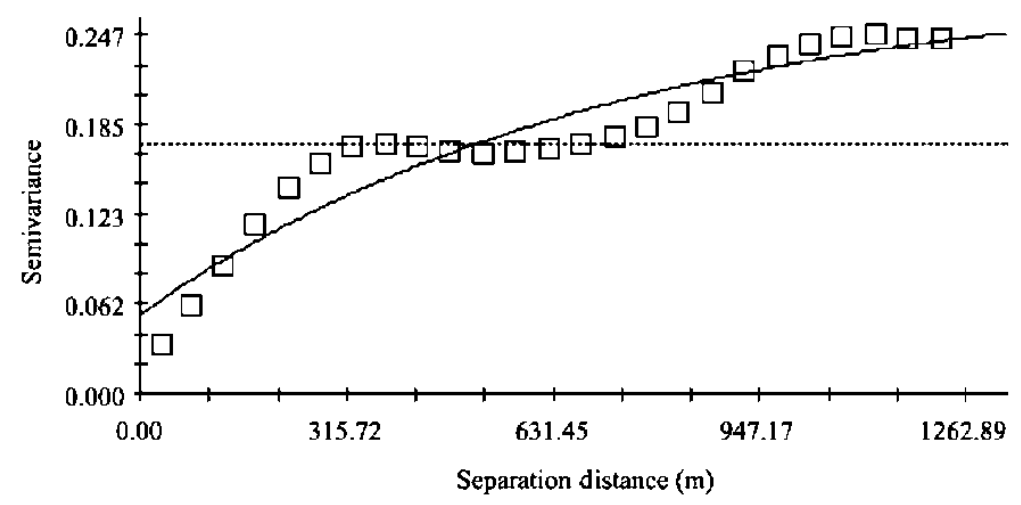

Exponential model $(\mathrm{Co}=0.054 ; \mathrm{Co}+\mathrm{C}=0.285 ; \mathrm{Ao}=725.00 ; \mathrm{RSS}=0.008)$

Figure 2. Exponential semivariogram model used for the analysis. Where Co is nugget, $\mathrm{Co}+\mathrm{C}$ is sill, Ao is range, and RSS (residual sums of squares) provides a measure of the fitness of the model to the data. 
Where $P(i, j)$ is the spatial co-occurrence matrix element, $R(i)$ is the grey-level value for the row, and $C(j)$ is the grey-level value for the column.

\section{Results}

The LDA classifier demonstrated that there was a difference in the classification accuracy based on the different input variables used in the procedure. The lowest overall classification accuracy was $47 \%\left(K_{\text {hat }}=0.35\right)$ when using the original six spectral bands. Using three grey-level co-occurrence texture variables derived from the original spectral data generated $64 \%$ classification accuracy $\left(K_{\text {hat }}=0.54\right)$. Adding the texture variables to the six spectral bands increased the overall accuracy to $77 \%$ overall $\left(K_{\text {hat }}=0.72\right)$. Finally, the accuracy was increased to $86 \%$ $\left(K_{\text {hat }}=0.82\right)$ when texture was derived from the kriging surface rather than the original image data.

All classes increased in accuracy when texture was used together with the spectral response patterns. In previous work (Franklin et al. 2001) it was suggested that sometimes accuracy in all classes will not be increased when texture variables are added; in another study, Franklin et al. (2000) showed that a few classes actually decreased in accuracy. The texture variables were thought to have contributed greater variance than could be handled by a statistical classifier. In the present study, classes of pure conifer and deciduous species were among the most accurately classified using spectral response patterns alone; for example, aspen trees were always the most accurately classified in these tests. The mixed-wood stands were classified with the least accuracy, but increased most when texture was used to the analysis. These mixed-wood stands were also the classes that showed the largest increase in accuracy following the kriging procedure. However, the accuracy of classes from these stands might still be considered too low (e.g. mixed-wood plots containing three or more species of trees or two or more canopy layers were less than $75 \%$ correct in the classification).

The maps contained in figure 3 illustrate the differences in the classification spatially over the study area. The large aspen stand in the central part of the map is apparent as a contiguous class in these maps; in figure 3(a), generated with the spectral data alone, the mixed-wood class confusion is apparent in the large extent of the various mixed classes, which is shown in figure $3(b)$ as well. The confusion is reduced in figure $3(c)$, when three texture channels (derived from original spectral bands) were added, however, some small aspen stands were classified incorrectly because of the texture data. In figure $3(d)$, when the classifier used the kriging surface texture and the spectral response pattern together, these classes were reduced in area and subsequently the stands appear to be more accurately portrayed. The influence of the spatial filtering is also apparent in these four maps; the map (figure $3(d)$ ), based on the geostatistical procedure, contains fewer small parcels and less 'salt-and-pepper' noise. This map, more accurate, also appears to be a more realistic depiction of stand homogeneity - the spatial arrangement and internal homogeneity of these classes more closely resemble the polygonal strata used in standard aerial photointerpretation-based forest stand mapping.

\section{Conclusion}

The accuracy of forest classification using fine spatial resolution remotely sensed data can be increased using image texture. The steps used to prepare the input data, and the type of texture variables selected, are among the many factors that can strongly influence the resulting forest classification accuracy. In this study, image 


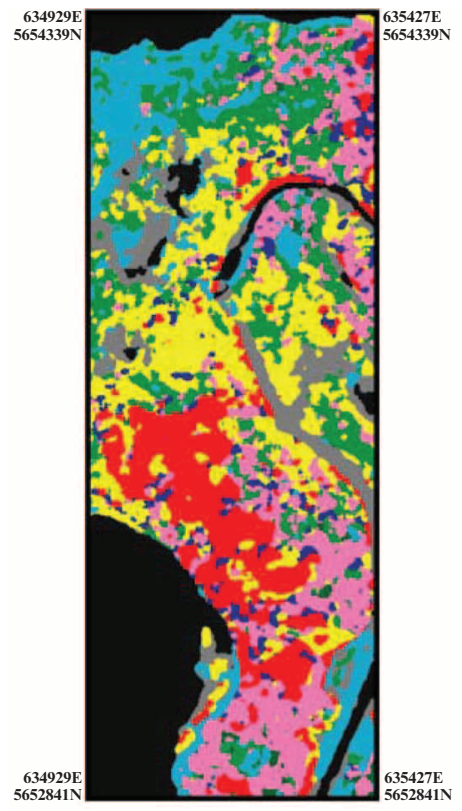

(a)

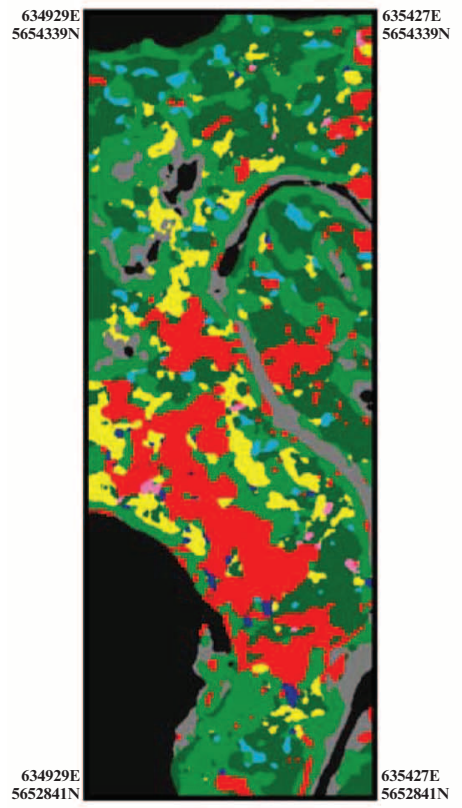

(c)

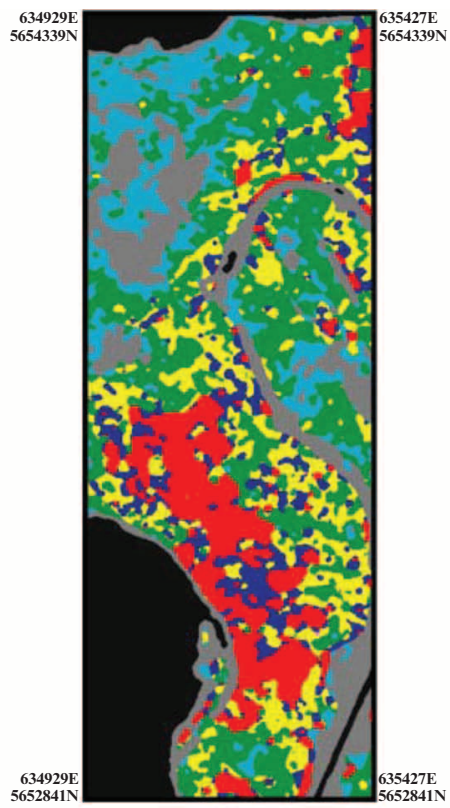

(b)

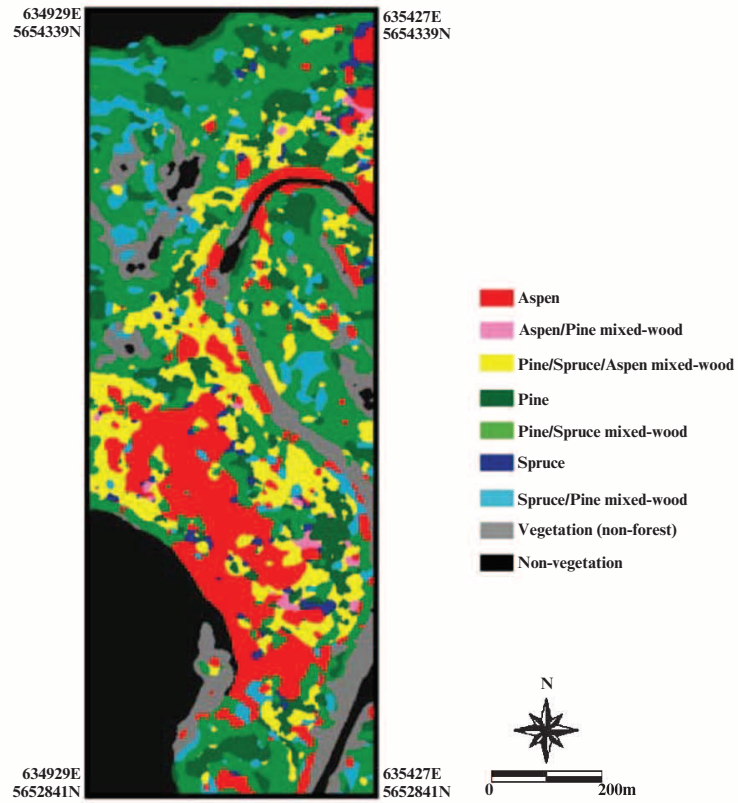

$(d)$

Figure 3. Classification maps based on $(a)$ spectral response patterns alone (overall accuracy $=47 \%$ ); (b) kriging surface alone (overall accuracy $=64 \%$ ); (c) spectral patterns with texture derived from original spectral bands (overall accuracy $=77 \%$ ); (d) spectral patterns and texture derived from the geostatistical surface (overall accuracy $=86 \%$ ).

grey-level co-occurrence texture variables extracted following a geostatistical analysis of airborne sensor images were used in pure and mixed-wood stands in Alberta; $86 \%$ overall classification accuracy was achieved in seven forest classes. 
This is an increase in accuracy over that which was obtained using the spectral data alone, the texture data alone, or the spectral data plus texture derived from the original image bands.

\section{Acknowledgments}

Funding was provided by the Canadian Forest Service and the Natural Sciences and Engineering Research Council of Canada. L. Monika Moskal and Graham Gerylo are thanked for their assistance in the collection of the field data. Two anonymous reviewers provided many helpful comments to improve the manuscript.

\section{References}

CARR, J. R., 1996, Spectral and textural classification of single and multiple band digital images. Computers and Geosciences, 22, 849-865.

Carr, J. R., and Pellon De Miranda, F., 1998, The semivariogram in comparison to the co-occurrence matrix for classification of image texture. IEEE Transactions on Geoscience and Remote Sensing, 36, 1945-1952.

Curran, P. J., 1988, The semivariogram in remote sensing: an introduction. Remote Sensing of Environment, 24, 493-507.

Franklin, S. E., Hall, R. J., Moskal, L. M., Maudie, A. J., and Lavigne, M. B., 2000, Incorporating texture into classification of forest species composition from airborne multispectral images. International Journal of Remote Sensing, 21, 61-79.

Franklin, S. E., Maudie, A. J., and Lavigne, M. B., 2001, Using spatial co-occurrence texture to increase forest structure and species composition classification accuracy. Photogrammetric Engineering and Remote Sensing, 67, 849-855.

Gong, P., and HowARTH, P. J., 1992, Frequency-based contextual classification and greylevel vector reduction for land-use identification. Photogrammetric Engineering and Remote Sensing, 58, 423-437.

Gray, L., Freemantle, J., Shepherd, P., Miller, J., Harron, J., and Hersom, C., 1997, Characterization and calibration of the CASI airborne imaging spectrometer for BOREAS. Canadian Journal of Remote Sensing, 23, 188-195.

Haralick, R. M., Shanmugam, K., and Dinstein, I., 1973, Textural features for image classification. IEEE Transactions on Systems, Man, and Cybernetics, SMC-3, 610-621.

LÉvesque, J., and King, D. J., 1999, Airborne digital camera image semivariance for evaluation of forest structural damage at an acid mine site. Remote Sensing of Environment, 68, 112-124.

Marceau, D. J., Howarth, P. J., Dubois, J. M., and Gratton, D. J., 1990, Evaluation of the grey-level co-occurrence matrix method for land-cover classification using SPOT imagery. IEEE Transactions on Geoscience and Remote Sensing, 28, 513-519.

Matheron, G., 1963, Principles of geostatistics. Economic Geology, 58, 1246-1266.

Muinonen, E., Maltamo, M., Hyppänen, H., and Vainikainen, V., 2001, Forest stand characteristics estimation using a most similar neighbor approach and image spatial structure information. Remote Sensing of Environment, 78, 223-228.

Oliver, M. A., Webster, R., and Slocum, K., 2000, Filtering SPOT imagery by kriging analysis. International Journal of Remote Sensing, 21, 735-752.

RICHTER, R., 1990, A fast atmospheric correction algorithm applied to Landsat TM images. International Journal of Remote Sensing, 11, 159-166.

Robertson, G. P., 2000, GeoStatistics for the Environmental Sciences User's Guide, Version 5 (Michigan: Gamma Design Software).

Treitz, P., and Howarth, P., 2000, High spatial resolution remote sensing data for forest ecosystem classification: an examination of spatial scale. Remote Sensing of Environment, 72, 268-289.

Van Meirvenne, M., and Goovaerts, P., 2002, Accounting for spatial dependence in the processing of multi-temporal SAR images using factorial kriging. International Journal of Remote Sensing, 23, 371-387.

Wen, R., and SindING-LARSEN, R., 1997, Image filtering by factorial kriging-sensitivity analysis and application to Gloria side-scan sonar images. Mathematical Geology, 29, $433-467$. 